\title{
O TRANSFEMINISMO E O RECORTE DE CLASSE
}

\author{
Helena Santos Braga de Carvalho ${ }^{1}$ \\ Letícia Soares Zampiêr ${ }^{2}$
}

\section{Resumo}

O presente trabalho consiste em uma análise em relação ao transfeminismo brasileiro levando em consideração a diferença de classe entre as mulheres trans e travestis traçando também uma comparação em relação aos outros segmentos feministas e uma crítica às produções de conhecimentos em diferentes áreas das ciências humanas e da saúde em relação à transexualidade. O objetivo do trabalho foi de mapear e discutir o que a literatura tem publicado acerca do tema. A partir das leituras, foi realizada análise de conteúdo para o enriquecimento do trabalho exploratório do material que nos proporcionou três eixos para o desenvolvimento deste trabalho: o transfeminismo e suas pautas e agendas, a produção cientifica acerca das mulheres transexuais e travestis e o recorte de classe. O transfeminismo ainda é um segmento recente que possui seus espaços de discussão limitados. Notamos que as pautas levantadas e discutidas atualmente pelo transfeminismo são de extrema importância para a população trans e para o enriquecimento das discussões dentro dos movimentos feministas. Porém, muitas pautas se encontram fora da realidade social de grande parte dessa população, que se mantêm a margem com pouco ou sem espaço de discussão ou de luta por seus direitos.

Palavras-Chave: Transfeminismo; Feminismo; Gênero; Classe Social; Marcadores de diferença.

\section{Sobre o Transfeminismo}

Partindo de uma reflexão em relação às mudanças ocorridas no campo dos estudos de gênero com influências dos movimentos feministas, podemos perceber ainda uma negligência por parte de algumas vertentes do movimento feminista. No passado, e ainda hoje, pautas raciais como a das mulheres negras foram consideradas inferiores e de menor importância como, por exemplo, através do mito que as mulheres "ganharam" o direito ao trabalho, situação que nunca considerou o fato das mulheres negras já trabalharem muito antes das mulheres brancas, por exemplo. As invisibilidades

\footnotetext{
${ }^{1}$ Bacharela Interdisciplinar em Ciências Humanas pela UFJF; Graduanda do curso de Ciências Sociais da UFJF; e-mail: helenasbc@ hotmail.com

${ }^{2}$ Graduanda do curso de Psicologia da UFJF; e-mail: le zampier@hotmail.com

CSOnline - Revista Eletrônica de Ciências Sociais, Juiz de Fora, n. 23 (2017), pp. 282- 294
} 
produzidas pelo feminismo branco burguês ocidental não são de hoje e atualmente em nossos contextos podemos perceber que, ao passo que se menosprezam e hierarquizam pautas raciais e de classe no movimento, adiciona-se uma invisibilidade cisgenera ${ }^{3}$.

Nesse sentido, em muitos âmbitos da nossa sociedade o entendimento da transexualidade ainda é perpassado por um discurso que toma como base argumentos biológicos e médicos, que tendem a patologizar, estigmatizar, marginalizar e excluir a transexualidade. No que se refere a mulheres trans e travestis é comum reconhecer críticas que se utilizam desse discurso para reproduzirem o preconceito e a transfobia. Não é raro ver a ideia que mulheres trans e travestis não são mulheres por causa da genitália. Um dos perigos da utilização de argumentos biológicos e médicos para a explicação ou justificação de questões de segregação e exclusão é repetir e sustentar uma das principais e mais fortes formas de pensamento responsáveis por diminuir e suprimir as mulheres ao longo da história. Pautar e direcionar discursos biologizantes ou que buscam a naturalização/essencialização da mulher - como "para ser mulher tem que ter vagina, útero e ovário" - às travestis e mulheres trans é também condenar e excluir outras mulheres cis que não são compatíveis a esses padrões e nem por isso configuramse menos mulheres ou femininas.

Ao lado destes argumentos biologizantes está também outro discurso com raízes bastante transfóbicas que defendem que as mulheres trans detiveram privilégios de homens cis antes de se assumirem trans ou travestis e começarem sua transição, por terem sido homens cis por determinado tempo, e que ainda manteriam esses privilégios, pegando para si apenas a parte feminina ou do "ser mulher" que lhes seria conveniente.

Assim, o transfeminismo surgiu, por conta da frustração com a falta de visibilidade e exclusão dentro do movimento feminista e a marginalização dentro do movimento LGBT (ALVES, 2015). Sua origem se dá no contexto da terceira onda ${ }^{4}$ do feminismo, sendo influenciado principalmente pelo feminismo da diferença, pelo feminismo negro e pelo feminismo pós-estruturalista. Para o feminismo da diferença, o gênero se refere aos traços que são socialmente designados como femininos ou

${ }^{3}$ Por falta de outro termo e por não ser o debate linguístico o ponto principal da discussão que pretendemos desenvolver neste trabalho, optamos pela utilização do termo "cisgênero" para designar pessoas não-trans mesmo sabendo que a ideia de "mulher/homem biológico" ou "mulher/homem normal" coloca as pessoas trans na categoria de anomalia e as desumaniza, sendo essa umas das pautas de debate do transfeminismo.

${ }^{4} \mathrm{O}$ termo "onda" frequentemente transmite a ideia de processos que se concluem de forma que uma "onda" substituísse a outra. Ressaltamos que nos referimos as "ondas" como abordagens simultâneas que apontam para continuidades entre os feminismos de forma que uma "onda" não acaba quando a outra surge.

CSOnline - Revista Eletrônica de Ciências Sociais, Juiz de Fora, n. 23 (2017), pp. 282- 294 
masculinos, tomando como base a biologia, e seu foco é a análise da construção dessas diferenças. Essas ideias vão contribuir para o transfeminismo através do seu foco na desconstrução do ideal de mulher, atrelado à biologia. As principais ideias absorvidas do feminismo negro foram a interseccionalidade e a valorização das experiências individuais, no caso trans. Do feminismo pós-estruturalista, a principal discussão adquirida foi a ideia da construção histórica e social das diferenças de gênero e, por tanto, a concepção de que existe uma grande variabilidade no que consideramos homem e mulher (JESUS, 2013).

Dessa forma o transfeminismo não deve ser entendido apenas como um segmento que acrescenta questões relacionadas às vivências trans aos debates feministas já existentes, mas sim como um movimento que levanta novas pautas e discussões, estabelecendo críticas a alguns segmentos e argumentos utilizados e muito reproduzidos dentro dos movimentos feministas.

Por consequência as principais pautas do transfeminismo são (ALVES, 2012):

1) As questões da feminilidade: ao beber da teoria queer, o transfeminismo questiona a construção binária e heteronormativa dos gêneros, que cobra das pessoas trans, até mais do que das pessoas cis, uma performance de gênero que se encaixe nessa matriz, correndo o risco de terem uma identidade deslegitimada caso fujam do padrão.

2) A despatologização das identidades trans: a remoção da transexualidade dos manuais diagnósticos (CID e DSM) é importante não só simbolicamente, para retirar o estereótipo de doença das identidades trans, mas também para proporcionar autonomia para que essas pessoas vivam seu gênero sem o rótulo de anomalia. E também para terem acesso aos procedimentos do processo transexualizador sem o laudo médico.

3) Cissexismo e a criação/utilização de um termo que designe as pessoas "normais": utilização do termo "cisgênero" para designar pessoas não-trans, uma vez que a ideia de "mulher/homem biológico" ou "mulher/homem normal" coloca as pessoas trans na categoria de anomalia e as desumaniza.

4) A separação da ideia de identidade de gênero como sendo sinônimo de sexualidade, e a visibilidade das pessoas trans não heterossexuais: na literatura médica, as pessoas trans são automaticamente vistas como heterossexuais ou assexuais. No entanto, se as pessoas cisgeneras experienciam diversas sexualidades (heterossexuais, homossexuais, bissexuais, pansexuais e assexuais), porque a sexualidade das pessoas trans não seria? 
5) Direitos Reprodutivos: luta contra a esterilização compulsória como prérequisito para atendimento médico, modificações corporais, casamento e retificação civil do gênero e do nome.

No que diz respeito à agenda política, Alves (2012) enumera sete pontos: 1) combate à violência cissexista/transfóbica; 2) direitos reprodutivos para todas/os; 3) princípio da agência;4) desconstrução das identidades binárias; 5) corpo-positividade e/ou empoderamento; 6) livre sexualidade; e 7) terminologia não essencialista.

\section{Pesquisa sobre a população Trans no Brasil: o que traz a literatura}

Vale destacar que este trabalho não se trata de uma revisão de literatura sistemática, porém, durante o levantamento de referências bibliograficas para o desenvolvimento deste, identificamos uma grande desproporção em relação as produções cientificas e academicas em relação a transexualidade e a travestilidade principalmente no que se refere aos temas estudados e associados as vivências trans que são, majoritariamente, ligadas a mulheres trans e travestis e as suas demandas. Investigando as ideias centrais dos artigos encontrados em bases de dados que concerne às produções científicas, foram encontrados um grande número de artigos relacionados a saúde, corpo e prostituição.

Amaral, Silva, Cruz, \& Toneli (2014) trazem uma revisão sistemática da literatura produzida sobre as vivências trans na última década. As autoras se depararam com o mesmo problema que nós: a dificuldade de distinção entre as categorias "transexual" e "travesti". Levando em conta que a fronteira entre esses termos é tênue tanto para as pessoas trans quando para outros pesquisadores, elas optaram por pesquisar os termos travesti, travestilidade e travestismo, considerando que os artigos encontrados abrangeriam as vivências trans como um todo. As autoras encontraram que os principais temas abordados quando o assunto são as travestis são o binômio "saúdedoença" e o corpo.

No que diz respeito à saúde, a maior parte das pesquisas são financiadas por agências de saúde, focando a prevenção/redução de danos ligados às drogas e às doenças sexualmente transmissíveis. Isso representa e reproduz a lógica de um programa governamental que investe e foca a atenção à saúde dessa população somente no âmbito de drogas e doenças sexualmente transmissíveis (DSTs). Nesse sentindo, Larissa Pelúcio (2006) trabalha como o modelo preventivo da AIDS distancia essa população da prevenção e do cuidado básico com a saúde em geral. Além disso, como 
esse estigma predomina e é reproduzido na sociedade. Outro fator apresentado é como o preconceito e a não qualificação dos profissionais e também de alguns usuários do SUS afastam essa população dos ambulatórios.

Em relação ao acesso aos serviços de saúde, as dificuldades relatadas nos estudos são diversas, já que muitas pessoas trans chegam aos serviços com poucas ou nenhuma informação básica sobre seus direitos e ainda sustentados por diversos mitos do senso comum acerca de suas condições (ARÁN e MURTA, 2009), para agravar este quadro, ao procurarem algum serviço público de saúde deparam-se com o despreparo e a inabilidade no atendimento por parte dos profissionais envolvidos no processo transexualizador ofertado, que por vezes apresentam ou reproduzem discursos preconceituosos (DUARTE, 2014) e patologizantes em relação à população transexual e principalmente as travestis.

Dentro da discussão saúde-doença, também é grande a problematização do processo transexualizador e a patologização das vivências trans, com a obrigatoriedade do laudo e do atendimento psiquiátrico e psicológico, como o único meio de acesso ao processo oferecido pelo SUS, caracterizado por seguir regras e regulamentações rígidas guiadas pelas literaturas médicas patologizantes que excluem do processo aqueles que não as cumprirem.

No que diz respeito ao corpo, aparecem principalmente as questões da "reconstrução", do "refazer", das "mudanças" e da "transformação" dos corpos nas vivências trans em sua maioria femininas. A hormonoterapia é vista como o primeiro passo para as construções dos corpos e consequentemente é cercada por idealizações de que as mudanças sociais estariam ligadas às transformações corporais. Assim, podemos perceber o esforço em fabricar corpos que "legitimem" as identidades a fim de alcançar reconhecimento e pertencimento social que as posicione em um lugar de aceitação. As dificuldades de acesso aos processos médicos institucionalizados ocasionam ao fato que muitas pessoas trans procurem outras formas de transformações corporais. Em relação à hormonização, isso ocorre através da automedicação. As autoras chamam atenção para alguns trabalhos que apontam a implicação da fabricação desse corpo para saúde, uma vez que o uso de silicone industrial e da hormonização sem acompanhamento médico especializado pode ter sérias consequências para a saúde.

A questão da prostituição também aparece recorrentemente, o que as autoras consideram problemático, uma vez que reitera e reproduz o estigma dessa população. Elas chamam atenção para a tendência recente de focar na luta pelo acesso e pela 
permanência na escola, garantindo a possibilidade da profissionalização, uma vez que a dificuldade de acesso à educação, e consequentemente a inserção em um mercado de trabalho formal, é apontado como um dos principais fatores que levariam a prostituição. Com a expansão do campo e das pesquisas relacionadas às sexualidades, ao gênero e às identidades nas últimas décadas, podemos perceber o aumento da frequência das discussões que deslocam a centralidade do debate do âmbito biomédico, apesar deste ainda estar muito presente. Temas como envelhecimento, adolescência, violência, educação, parentalidades/relações conjugais, raça, religião e política apareceram, mas com menos frequência ou como temas secundários dos estudos. As autoras pontuam especialmente a escassez de trabalhos relacionados à violência e ao acesso à educação como já dito anteriormente (AMARAL, SILVA, et al., 2014).

\section{$O$ recorte de classe}

Em nossas buscas nos deparamos com um número pequeno de textos que trabalhem como ponto central de discussão as especificidades das vivências trans associadas ao recorte de classe. Através de buscas que utilizavam o termo "travesti" observamos, a partir das produções e temáticas relacionadas, diferenças de demandas em relação às pautas transfeministas.

Pensando em uma distinção da origem da atribuição de diferentes estigmas entre travestis e transexuais um importante fator é a diferenciação da classe social e das consequências que pertencer a essa classe traz para a trajetória e para as vivências destas mulheres. O senso comum vinculado às travestis é de que estas são oriundas de classes sociais mais populares, com menor capital cultural, e devido as suas expressões de gênero e sexualidade estariam vinculadas ao "desvio" "moral" ou "comportamental". Já as transexuais viriam de classes médias e altas, com maior capital cultural, e seus "desvios" estariam vinculados a questões "mentais", direcionando estas a uma construção de identidade vinculada ao discurso médico.

Garcia (2009) traz em sua pesquisa a história de vida que mais se repete entre travestis de baixa renda: oriundas de família de baixa renda, histórico de homofobia na escola e na família, fuga para a "cidade grande" na expectativa de aceitação e encontrando a prostituição como única alternativa. Pelúcio (2011), ao perguntar para travestis da pista "Qual é o maior problema de saúde que as travestis enfrentam?", recebeu como resposta "depressão" e "drogas ilícitas", ambas associadas com a "pressão" sofrida cotidiana, que assume o caráter de rotina.

CSOnline - Revista Eletrônica de Ciências Sociais, Juiz de Fora, n. 23 (2017), pp. 282- 294 
Butler (2003) traz o conceito de abjeção para falar sobre negação da ontologia das pessoas trans por quebrarem as normativas binárias de gênero, dessa forma, as experiências trans são predominantemente marcadas pela recusa social de sua expressão de gênero, que leva a formas visíveis e invisíveis de violência, que não só causam sofrimento psíquico e físico, mas que muitas vezes podem levar à morte. Assim, apesar de considerarmos extremamente importante o fim do estigma e da associação entre travestis e prostituição, uso de drogas e DSTs, a vulnerabilidade e as circunstâncias sociais que levam essa população a essa realidade como única possibilidade de sobrevivência e muitas vezes sem a possibilidade de alteração dessas circunstancias não podem ser negligenciadas.

Um grande exemplo disto é no que diz respeito ao acesso a saúde, principalmente nos serviços públicos, onde as pessoas trans encontram dificuldades duplas: se reconhecidas como travestis, tem o cuidado básico automaticamente associado a DSTs, e se reconhecidas como transexuais, o acesso depende da aceitação da condição de patologização da transexualidade. Isso significa que o acesso à saúde está permanentemente associado à patologia e ao desvio. Podemos pensar esse ponto através das ideias de Foucault sobre biopoder: uma vez desviantes da normativa binária, essas pessoas são excluídas do "fazer viver" e são "deixadas para morrer" (FOUCAULT, 2005).

As mudanças corporais também esbarram com a saúde: uma vez que os procedimentos ofertados pelo SUS são de difícil acesso, grande parte da população trans têm dificuldades em acessar acompanhamentos médicos adequados. No entanto, muitas dessas pessoas desejam um resultado rápido, pois não aguentam as pressões sociais para "assumir um lado ou outro" e sair da ambiguidade, ainda não admissível em nossa sociedade.

Afim de conquistar um reconhecimento por parte do outro que as posicione em um lugar de aceitação, estudos apontam que as dificuldades atribuídas aos processos médicos acarretam ao fato que muitas transexuais e travestis optam por procurar outros meios de alcançar os objetivos de transformações corporais, muitas vezes prosseguindo por meios informais e até mesmo drogas ilegais, como os hormônios sem receita e o silicone industrial, que não raro podem levar a morte. Em relação à hormonização, isso ocorre através da automedicação, que normalmente se inicia através do compartilhamento informal de informações por pessoas sem especialização no assunto, frequentemente amigos e através da Internet, de forma que a atuação do médico cede CSOnline - Revista Eletrônica de Ciências Sociais, Juiz de Fora, n. 23 (2017), pp. 282- 294 
lugar a trocas informais e o acesso passa a ser mediado por expertises leigas. (GALINDO, MÉLLO e VILELA, 2013) Como a hormonização é vista como um dos principais e primeiros meios de construção e alteração dos corpos, a autoadministração de hormônios é recorrente. Muitas vezes este procedimento não é iniciado com acompanhamento médico especializado, mas sim, através da troca de informações e experiências. O compartilhamento de informações e saberes entre a população transexual e travesti se constitui como um dos grandes vetores por onde se adquire os conhecimentos iniciais para começar as modificações corporais. Assim, é possível acessar informações frequentemente divulgadas por pessoas que já iniciaram a hormonioterapia, ou que passaram por outras experiências com o uso de hormônios, e possuem conhecimento sobre os medicamentos, seus efeitos e como devem ser administrados. Apesar das informações compartilhadas serem explicadas de forma cuidadosa, os riscos e efeitos colaterais são aspectos muito relevantes e seriamente considerados já que cada organismo responde de forma diferenciada a cada substancia, de forma que é reconhecida a importância de consultas a médicos especializados, mesmo sendo uma pequena parcela dessa população que de fato tem acesso a esse acompanhamento. Dessa forma, a maioria das travestis que estão "na rua" ou "na pista" recorre a esses meios informais para terem obterem informações acerca aos processos de saúde e de construção dos corpos, já que encontram mais e maiores dificuldades nos meios formais e institucionalizados de saúde, principalmente aos procedimentos oferecidos pelo processo transexualizador oferecido pelo SUS, por nem sempre desejarem seguir ou se enquadrar nas regras rígidas do processo.

Nesse sentido, a diferença de classe social e, consequentemente, de acesso aos serviços de saúde bem como de condições materiais, é fundamental para a construção dos corpos e performances das travestis e transexuais. De acordo com Carvalho (2016) a atribuição de marginalidade às mulheres "travestis" parece produzir uma "rotina" que levaria a um determinado processo de cuidado e produção dos corpos e de uma determinada feminilidade, enquanto a rotulação psiquiátrica das mulheres "transexual" produziria outra "rotina" e consequentemente outros cuidados e construções dos corpos e feminilidades distintas.

\section{Transfeminismo para quem?}

Levando em consideração os pontos apresentados nos itens anteriores, nossa proposição é que as pautas apresentadas como fundamento do transfeminismo não CSOnline - Revista Eletrônica de Ciências Sociais, Juiz de Fora, n. 23 (2017), pp. 282- 294 
abordam todas as vivências trans. Apesar de serem importantíssimas, elas caem no mesmo problema do feminismo clássico da década de 1970: propõem pautas que não abrangem todas as pessoas trans.

Retomando as pautas do transfeminismo uma a uma, podemos perceber nitidamente essa falha. É pautado o respeito às diferentes formas de expressão de gênero, mas na prática ainda é visível a hierarquização das transexuais e travestis. Além disso, se a despatologização é essencial para o acesso à saúde, também é a desassociação entre travestilidade e DSTs. É importante pautar questões teóricas, como o cissexismo da nomenclatura e as diferenças entre orientação sexual e identidade de gênero, mas até que ponto essa discussão é significativa para a população que está na rua ou "na pista" lutando por condições básicas para sobreviver?

Podemos perceber um afastamento das questões de classe quando se trata de transexuais e travestis, da falta de formulações que questionem a marginalidade das pessoas que fogem as normas de gênero e sexualidade no geral. Assim, nos deparamos com um transfeminismo que pouco se importa com as condições materiais que determinam diversos vetores de opressão, que não reconhece que cada aspecto compreendido das opressões impostas, das mais supérfluas às mais complexas, também estão ligados e têm como fator de propulsão, a classe social.

Desta forma, o movimento, em muitos aspectos, se desqualifica ao abandonar ou tornar secundária luta de classes em suas pautas e agenda política. Isso faz com que ele acabe perdendo as mulheres que, muitas vezes, ficam marginalizadas, segregadas, excluídas e abandonadas. Perdem porque trazer uma discussão de classe para dentro desse movimento só faria por enriquecê-lo, abarcando outras visões e experiências. Mas, ao invés disso, simplesmente deixam que se perca tal oportunidade, ignorando anos de construção do movimento feminista classista, ao replicar em alguns aspectos os ideais "burgueses" que tanto foram criticados no feminismo clássico.

É possível constatar que as travestis não lidam somente com as opressões institucionalizadas nos lugares/espaços que ocupam, mas também com dentro dos próprios movimentos sociais. Apesar destes espaços “informais" serem construídos com o objetivo de acolher e fortalecer as populações aos quais são destinados, eles acabam sendo locais em que as diferentes formas de violência presentes na sociedade são perpetuadas e, não, combatidas. Dessa forma, as travestis hoje ainda são minoria dentro da minoria, no que se refere às pautas e agendas políticas do transfeminismo.

CSOnline - Revista Eletrônica de Ciências Sociais, Juiz de Fora, n. 23 (2017), pp. 282- 294 
No Brasil o coletivo TransRevolução é destaque no que se refere a luta por direitos das travestis e transexuais se engajando nas pautas referentes a classe atingindo uma importante parcela da população $\mathrm{T}$ que se encontram em situações de maior vulnerabilidade. O coletivo fundado por Giselle Meirelles Kuzattis Cassani e que possui atualmente como nome de referência a ativista e militante Indianara Alves Siqueira desenvolve projetos, encontros e debates em relação aos direitos das travestis e transexuais no que se refere a cidadania, saúde, violência e educação. Através do projeto PreparaNem, curso preparatório direcionado para travestis, transexuais, transgêneros e outras pessoas em situação de vulnerabilidade social e preconceito de gênero que desejam ingressar em universidades públicas do país, o grupo ficou conhecido nacionalmente. Este é um excelente exemplo das várias articulações e diferentes formas de resistências que existem e sobrevivem no país, apontando para a força e poder de articulação política e social dessa população. Assim, da mesma forma que pensamos os movimentos feministas como algo plural, a tendência é que o transfeminismo assuma diferentes articulações e que existam múltiplas expressões do transfeminismo de forma que as pautas e agendas politicas contemplem cada vez mais as diferentes demandas e as inúmeras identidades de gênero.

\section{Conclusão}

O transfeminismo no Brasil é considerado um movimento recente e de fato possui suas limitações visto que ainda existem muitas diferenças em relação às demandas e lutas em relação à legitimidade das identidades travestis e transexuais. Mesmo jovem, esse segmento do feminismo já contribuiu e ainda contribui para o crescimento do debate dentro do movimento feminista. O transfeminismo hoje é o principal responsável por empoderar as transexuais e as travestis, motivando-as a tornarem-se sujeitos de suas próprias histórias, e a utilizar seus próprios discursos para se desvincular do discurso medico biologizante, de forma que possam lidar com as questões do corpo, de saúde e judiciais sem depender do discurso do outro sobre sua autonomia e vivências.

Assim, considerando a trajetória do feminismo e o surgimento do transfeminismo no Brasil, notamos que as pautas levantadas e discutidas atualmente pelo transfeminismo são de extrema importância para a população trans e para o 
enriquecimento das discussões dentro dos movimentos feministas. Porém, essas pautas ainda se mostram discutindo algumas questões que estão distantes da realidade social de grande parte dessa população, principalmente em relação a realidade das mulheres que se identificam como travestis, mantendo essa parte da população à margem com pouco ou sem espaço de discussão ou de luta por seus direitos. A partir disso, nossas observações são direcionadas ao fato das discussões de classe social não estarem presentes nem na militância e nem nos meios científicos e acadêmicos, visto que para o desenvolvimento deste trabalho notamos a escassez de produções que associem os temas de classe social a mulheres transexuais e travesti. $\mathrm{O}$ transfeminismo se constitui, portanto, um segmento recente que possui seus espaços de discussão ainda limitados, mas que já apresenta a potência de suas articulações.

Spivak (2010) coloca em xeque o papel do cientista como mediador e como aquele que se julga habilitado a falar pelos sujeitos e grupos, em sua maioria silenciados, e que dessa forma reproduz as estruturas de poder e de subalternidade. Assim, esta autora sugere que nas produções de conhecimento acadêmico devem-se criar espaços em que seja possível que estes sujeitos falem e sejam ouvidos, trabalhando contra a subalternidade, criando espaços menos hierarquizados. Sabendo disto, achamos de suma importância nos posicionamos enquanto feministas, conscientes que nossos olhares, leituras e real compreensão que esta temática e as vivências trans está perpassado por nossos olhares cisgeneros, apesar de nossas tentativas de sempre buscarmos romper, na medida do possível, com a linearidade das produções acadêmicas, pesquisas e projetos de extensão, nos mantendo atentas para novas discussões que diz respeito não somente a essa população, mas representa sim a articulação e conquista de direito e espaço político de todas as mulheres em suas múltiplas expressões de gênero.

\section{Referências}

ADRIÃO, K. G. Feminismo, Psicologia, e Justiça social: um encontro possível? Uma entrevista com Michelle Fine. Psicologia \& Sociedade, v. 27, n. 3, p. 479-486, 2015. 
ALVES, H. Introdução ao transfeminismo. Transfeminismo, 1 Outubro 2012. Disponivel em: <https://transfeminismo.com/introducao-ao-transfeminismo/>.

ALVES, H. O que é e porque precisamos do transfeminismo. In: (ORG.), L. S. A quem pertence o corpo da mulher? Reportagens e ensaios. [S.1.]: Reporter Brasil, 2015. Disponivel em: $<$ https://edisciplinas.usp.br/pluginfile.php/371874/mod_resource/content/0/Encontro\%2 06\%20-\%20O-que-\%C3\%A9-Transfeminismo.pdf >.

AMARAL, M. D. S. et al. Do travestismo às travestilidades: uma revisão do discurso acadêmico no Brasil entre 2001-2010. Psicologia \& Sociedade, v. 26, n. 2, p. 301-311, 2014.

ARÁN, M.; MURTA, D. Do diagnóstico de transtorno de identidade de gênero às redescrições da experiência da transexualidade: uma reflexão sobre gênero, tecnologia e saúde. Physis: Revista de Saúde Coletiva, v. 19, n. 1, p. 15-41, 2009.

BUTLER, J. Problemas de Gênero. Rio de Janeiro: Editora Civilização Brasileira, 2003.

CARVALHO, M. F. D. L. "Travesti", "mulher transexual" "homem trans" e "não binário": interseccionalidades de classe e geração na produção de identidades políticas. [S.1.]: [s.n.]. 2016.

CRENSHAW, K. Mapping the margins: intersectionality, identity politics and violence against women of color. In: FINEMAN, M. A.; MYKITIUK, R. The public nature of private violence. Nova York: Routledge, 1994. p. 93-118.

DUARTE, M. J. D. O. Diversidade Sexual, Políticas Públicas e Direitos Humanos: Saúde e Cidanania LGBT em Cena. Temporalis, v. 1, n. 27, p. 77-89, agosto 2014. FOUCAULT, M. Aula de 17 de março de 1976. In: FOUCAULT, M. Em defesa da sociedade. São Paulo: Martins Fontes, 2005. p. 285-315.

GALINDO, D.; MÉLLO, R. P.; VILELA, R. Modos de Viver Pulsáteis: Navegando nas Comunidades Trans sobre Hormônios. Revista Polis e Psique, v. 3, n. 2, p. 19-42, 2013. 
GARCIA, M. R. V. Alguns aspectos aspectos da construção do gênero entre travestis de baixa renda. Psicologia USP, v. 20, n. 4, p. 597-618, 2009.

HIRATA, H. Gênero, classe e raça: Interseccionalidade e consubstancialidade das relações sociais, v. 26, n. 1, p. 61-73, Junho 2014.

JESUS, J. G. D. Feminismo e identidade de gênero: elementos para a construção da teoria transfeminista. Seminário Internacional Fazendo Gênero 10. Florianópolis: [s.n.]. 2013.

KERGOAT, D. Ouvriers = ouvrières? Propositions pour une articulation théorique de deux variables: sexe et classe sociale. Critiques de l'Économie Politique, v. 5, p. 6597, 1978.

MISKOLCI, R. A Teoria Queer e a Sociologia: o desafio de uma analítica da normalização. Sociologias, n. 21, p. 150-182, 2009.

PELÚCIO, L. Três casamentos e algumas reflexões: notas sobre conjugalidade envolvendo travestis que se prostituem. Revista Estudos Feministas, v. 14, n. 2, p. 522-534, 2006.

PELÚCIO, L. Marcadores Sociais da Diferença nas Experiências Travestis de Enfrentamento à aids. Saúde e Sociedade, v. 20, n. 1, p. 76-85, 2011.

SCOTT, J. W. O enigma da igualdade. Revista de Estudos Feministas, Florianópolis, v. 13, n. 1, p. 11-30, 2005.

SPIVAK, G. C. O. Pode o subalterno falar? Belo Horizonte: Editora UFMG, 2010. 